\title{
Biosynthesis of Zinc Oxide Nanoparticles Using Ixora Coccinea Leaf Extract-A Green Approach
}

\author{
Snehal Yedurkar ${ }^{1 *}$, Chandra Maurya ${ }^{1}$, Prakash Mahanwar ${ }^{2}$ \\ ${ }^{1}$ Department of Chemistry, Guru Nanak Khalsa College, Mumbai, India \\ ${ }^{2}$ Department of Polymer and Surface Engineering, Institute of Chemical Technology, Mumbai, India \\ Email: *snehaly8@gmail.com
}

How to cite this paper: Yedurkar, S., Maurya, C. and Mahanwar, P. (2016) Biosynthesis of Zinc Oxide Nanoparticles Using Ixora Coccinea Leaf Extract-A Green Approach. Open Journal of Synthesis Theory and Applications, 5, 1-14.

http://dx.doi.org/10.4236/ojsta.2016.51001

Received: December 10, 2015

Accepted: January 16, 2016

Published: January 25, 2016

Copyright $\odot 2016$ by authors and Scientific Research Publishing Inc. This work is licensed under the Creative Commons Attribution International License (CC BY 4.0).

http://creativecommons.org/licenses/by/4.0/

\begin{abstract}
Green synthesis of metal oxide nanoparticles using plant extract is a promising alternative to traditional method of chemical synthesis. In this paper, we report the synthesis of nanostructured zinc oxide particles by biological method. Highly stable and spherical zinc oxide nanoparticles are produced by using zinc acetate and Ixora coccinea leaf extract. Formation of zinc oxide nanoparticles has been confirmed by UV-Vis absorption spectroscopy, X-ray diffraction (XRD), Fourier transform infrared spectroscopy (FTIR), Dynamic light scattering analysis (DLS), zeta potential study and Scanning Electron Microscope with the Energy Dispersive X-ray studies (EDX). Dynamic light scattering analysis shows average particle size of $145.1 \mathrm{~nm}$ whereas high zeta potential value confirms the stability of formed zinc oxide nanoparticles. The Scanning Electron Microscope reveals spherical morphology of nanoparticles and Energy Dispersive X-ray analysis confirms the formation of highly pure zinc oxide nanoparticles. The zinc oxide nanoparticles from Ixora coccinea leaves are expected to have applications in biomedical, cosmetic industries, biotechnology, sensors, medical, catalysis, optical device, coatings, drug delivery and water remediation, and also may be applied for electronic and magneto-electric devices. This new eco-friendly approach of synthesis is a novel, cheap, and convenient technique suitable for large scale commercial production.
\end{abstract}

\section{Keywords}

Zinc Oxide Nanoparticles, Ixora coccinea, Green Synthesis, XRD, DLS, EDX

\section{Introduction}

Nanoparticles are of great interest due to their extremely small size and large surface area to volume ratio, which lead to both chemical and physical differences in their 
properties (e.g. mechanical properties, biological and sterical properties, catalytic activity, thermal and electrical conductivity, optical absorption and melting point) compared to bulk of the same chemical composition. Therefore, design and production of materials with novel applications can be achieved by controlling shape and size at nanometre scale. Nanoparticles exhibit size and shape-dependent properties which are of interest for applications ranging from biosensing and catalysts to optics, antimicrobial activity, computer transistors, electrometers, chemical sensors, and wireless electronic logic and memory schemes. These particles also have many applications in different fields such as medical imaging, nanocomposites, filters, drug delivery, and hyperthermia of tumors [1]-[3].

Over the past few decades, inorganic nanoparticles, whose structures exhibit significantly novel and improved physical, chemical, and biological properties and functionality due to their nano-scale size, have elicited much interest. Recent studies have shown that nanoparticles of some materials including metal oxides, can induce cell death in eukaryotic cells [4]-[6] and growth inhibition in prokaryotic cells due to cytotoxicity.

Among the metal oxide nanoparticles, zinc oxide nanoparticles have drawn attention of many researchers for their unique optical and chemical behaviors which can be easily tuned by changing the morphology. Within the large family of metal oxide nanoparticles, zinc oxide nanoparticles have been used in various cutting edge applications like electronics, communication, sensor, cosmetics, environmental protection, biology and medicinal industry [7]-[11]. Moreover, zinc oxide nanoparticles have a tremendous potential in biological applications like biological sensing, biological labelling, gene delivery, drug delivery and nanomedicines.

Different physical and chemical processes are currently widely used to synthesize metal nanoparticles, which allow one to obtain particles with the desired characteristics. However, these production methods are usually expensive, labor-intensive, and are potentially hazardous to the environment and living organisms. Thus, there is an obvious need for an alternative, cost-effective and at the same time safe and environmentally sound method of nanoparticle production [12]-[14]. During the past decade, it has been demonstrated that many biological systems, including plants and algae [15], bacteria [16], yeast [17] and fungi [18] can transform inorganic metal ions into metal nanoparticles via the reductive capacities of the proteins and metabolites present in these organisms.

Several conventional methods have been used for synthesis of zinc oxide nanoparticles like chemical vapor synthesis [19], laser ablation [20], solvothermal [21], thermal decomposition [22] and sol-gel method [23]. However, these production methods are usually expensive, labor-intensive, and are potentially hazardous to the environment and living organisms. Chemical methods lead to the presence of some toxic chemicals adsorbed on the surface that may have adverse effects in medical application [24]. Some problems that are often experienced in synthesizing metal nanoparticles are stability and aggregation, control of crystal growth, morphologies, sizes, and distribution, which 
are important issues and continue to be solved. Thus, there is an obvious need for an alternative, cost-effective and at the same time safe and environmentally sound method of nanoparticle production. Therefore there is a need for "green chemistry" that offers numerous benefits of eco-friendliness and compatibility for pharmaceutical and other biomedical applications, where toxic chemicals are not used for the synthesis protocol. The use of agricultural wastes [25] or plants and their parts [26]-[27] has emerged as an alternative to chemical synthetic procedures because it does not require elaborate processes such as intracellular synthesis and multiple purification steps or the maintenance of microbial cell cultures [28]. Along with this plants also provide a better platform for nanoparticle synthesis as they are free from toxic chemicals as well as provide natural capping agents [29]-[30].

Few papers reported the biosynthesis of zinc oxide nanoparticles using plant extracts such as Aloe barbadensis miller [31], Physalis alkekengi [32], Parthenium hysterophorus [33], Zingiber officinale (ginger) [34], Azadirachta indica [35], Ocimum basilicum L. var. Purpurascens [36], Medicago sativa [37], Anisochilus carnosus [38], milky latex of Calotropis procera [39], Poncirus trifoliate plant dried fruits, Hibiscus rosasinensis [40] and fruit juice of Citrus aurantifolia [41]. In this regard using green methods in the synthesis of zinc oxide nanoparticles has increasingly become a need of time. Green method using leaf extract of Ixora coccinea has been used for the first time for the synthesis of zinc oxide nanoparticles. Ixora coccinea Linn. (Rubiaceae), commonly known as jungle of geranium and red Ixora, is an evergreen shrub found throughout India. Depending on the medical condition, the flowers, leaves, roots, and the stem are used to treat various ailments in the Indian traditional system of medicine, the Ayurveda, and also in various folk medicines. Phyto-chemical studies indicate that the plant contains important phytochemicals such as lupeol, ursolic acid, oleanolic acid, sitosterol, rutin, lecocyanadin, anthocyanins, proanthocya-nidins, glycosides of kaempferol and quercetin. Pharmacological studies suggest that the plant possesses antioxidative, antibacterial, gastroprotective, hepatoprotective, antidiar-rhoeal, antinociceptive, antimutagenic, antineoplastic and chemopreventive effects [42]. Synthesis of gold nanoparticles in aqueous medium using flower extracts of Ixora coccinea as reducing and stabilizing agent has been reported by [42]. But there is no report available for the synthesis of zinc oxide nanoparticle by using any part of plant Ixora cocinea. Hence, in the present investigation, biological approach using leaf extract of Ixora coccinea as a reducing as well as surface stabilizing agent for the synthesis of zinc oxide nanoparticles has been reported. Synthesized product was characterized by the standard characterization techniques.

\section{Experimental}

\subsection{Materials}

Ixora coccinea leaves were collected from Institute of Chemical Technology campus, Matunga, Mumbai, India. The important compounds in the plant extract are hydroxyl and carbonyl groups. Both functional groups allowed plant extract to act as reducing agent. Functional groups present in the leaves extract of Ixora coccinea such as phenol- 
ics and alkaloids are responsible for capping thereby stabilization of nanoparticles reduced. Zinc acetate dihydrate $\left(\mathrm{Zn}\left(\mathrm{O}_{2} \mathrm{CCH}_{3}\right)_{2}\right.$ as metal ion precursor which act as zinc source and sodium hydroxide $(\mathrm{NaOH})$ as precipitating agent were purchased from Merck, India Pvt. Ltd. Distilled water was used throughout the reaction process.

\subsection{Preparation of the Leaf Extract}

Fresh leaves of Ixora coccinea were thoroughly cleaned with running tap water to remove debris and other contaminations, followed by distilled water and air dried at room temperature. Leaves were finely chopped into small pieces. The aqueous extract of sample was prepared by boiling the freshly collected cut leaves $(10 \mathrm{~g})$, with $100 \mathrm{~cm}^{3}$ of distilled water, at $60^{\circ} \mathrm{C}$ for about 20 minutes, until the color of the aqueous solution changes from watery to light brown. Then the extract was cooled to room temperature and filtered using whatman filter paper. The extract was stored in a refrigerator in order to be used for further experiments.

\subsection{Green Synthesis of Zinc Oxide Nanoparticles}

For the synthesis of zinc oxide nanoparticles, $50 \mathrm{~cm}^{3}$ of $0.5 \mathrm{M}$ zinc acetate dihydrate solution was prepared using distilled water. $1 \mathrm{~cm}^{3}$ aqueous leaf extract of Ixora coccinea was introduced into the above solution after 10 minutes of stirring. In order to maintain the $\mathrm{pH} 12,2.0 \mathrm{~mol} \cdot \mathrm{dm}^{-3}$ sodium hydroxide was used which resulted in a pale white aqueous solution. This was then placed in a magnetic stirrer for $2 \mathrm{hrs}$. The pale white precipitate was then taken out and washed over and over again with distilled water followed by ethanol to get free of the impurities. Then a pale white powder of zinc oxide nanoparticles was obtained after drying at $60^{\circ} \mathrm{C}$ in oven over night to give yield of 96.7\%. Graphical representation of the procedure is shown in Figure 1.

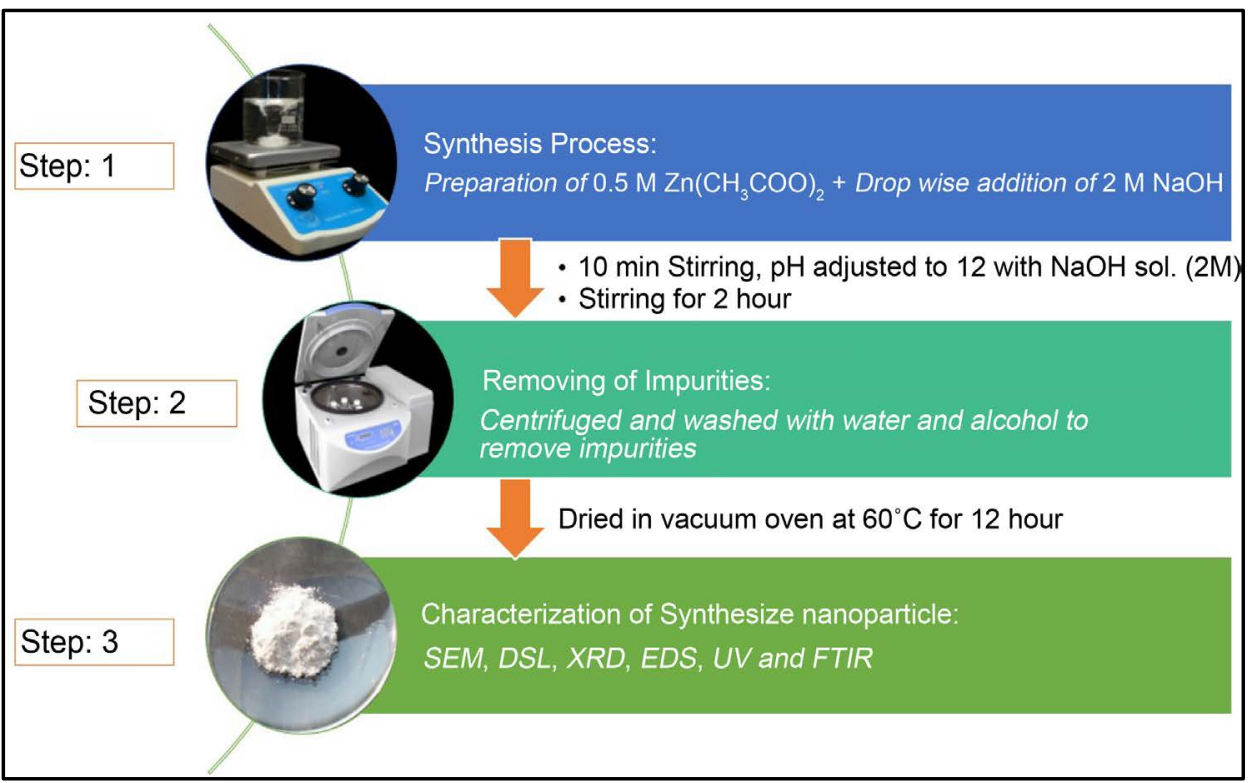

Figure 1. Graphical represtation for formation of zinc oxide nanoparticles. 


\subsection{Characterization of Zinc Oxide Nanoparticles}

The obtained zinc oxide nanoparticles were measured for its maximum absorbance using UV-Vis spectrophotometry. The optical property of zinc oxide nanoparticles was determined via ultraviolet and visible absorption spectroscopy in the range of 280 - 420 $\mathrm{nm}$. Structure of zinc oxide nanoparticles was analyzed by using X-Ray Diffraction (XRD) analysis. Particle size of synthesized nanoparticles was obtained by Dynamic light scattering analysis (DLS) and stability of the nanoparticles was checked by zeta potential measurement. External morphology i.e. shape of the nanoparticles were characterized by Scanning Electron Microscope (SEM). Elemental analysis was obtained from energy dispersive X-ray diffraction (EDX), which was attached with SEM.

\section{Results and Discussion}

\subsection{UV-Visible Spectral Analysis}

The optical absorption spectra of zinc oxide nanoparticles were recorded using UV/VIS 3000+ Double Beam UV Visible Ratio-Recording Scanning Spectrophotometer from Lab India (SKU: 174-0020) with dimensions of $(\mathrm{W} \times \mathrm{D} \times \mathrm{H}) /$ Weight $=540 \times 440 \times 390$ $\mathrm{mm} / 36 \mathrm{~kg}$. Spectral bandwidth of Spectrophotometer is $0.5,1,2,5 \mathrm{~nm}$ and wavelength is in the range of 190 to $1100 \mathrm{~nm}$. Figure 2 shows the UV-Vis absorption spectrum of zinc oxide nanoparticles. The absorption spectrum was recorded for the sample in the range of $280-420 \mathrm{~nm}$. The spectrum showed the absorbance peak at $340 \mathrm{~nm}$ corresponding to the characteristic band of zinc oxide nanoparticles [43].

\subsection{X-Ray Diffraction (XRD) Analysis}

The X-Ray diffraction (XRD) pattern of synthesized zinc oxide nanoparticles is shown in Figure 3. A normal focus diffractometer (RegakuMiniflex, Japan) source Cu target at

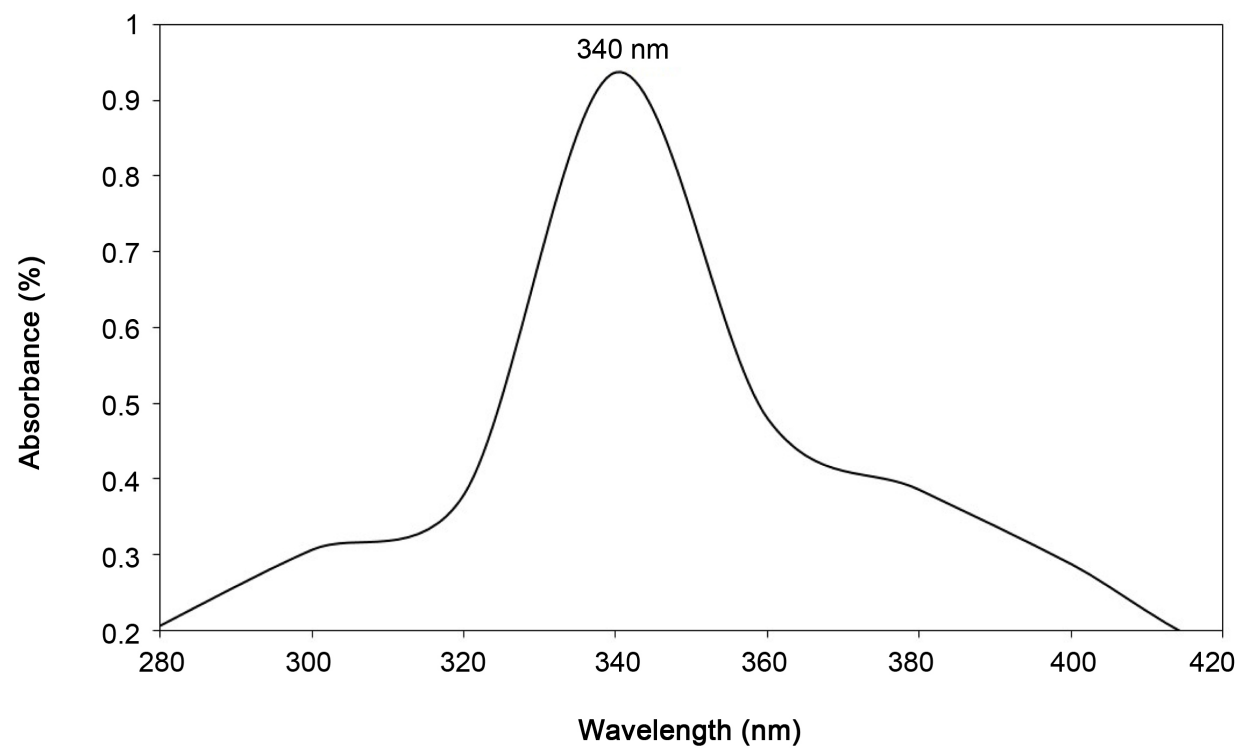

Figure 2. UV-Vis spectrum of synthesized zinc oxide nanoparticles. 


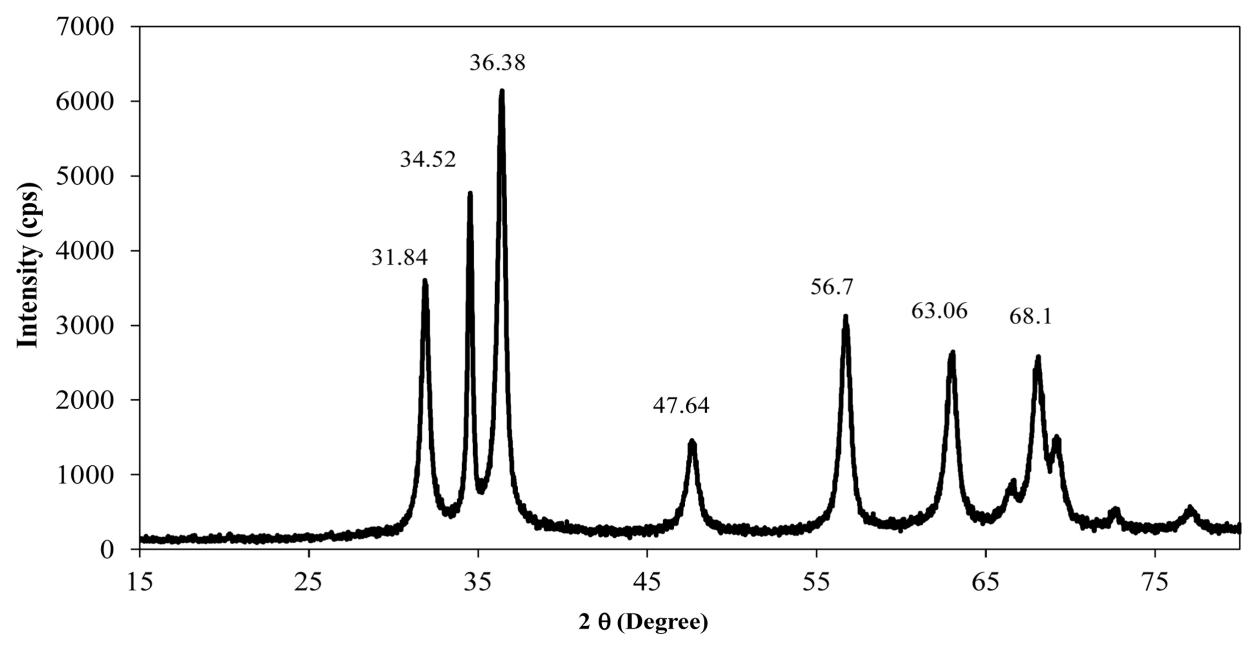

Figure 3. XRD pattern of synthesized zinc oxide nanoparticles.

$30 \mathrm{kV}$ and $15 \mathrm{~mA}$ was used with scan rate of $3 \% \mathrm{~min}$. The data recorded in the range $5 \theta$ $80 \theta$ and analyzed using Jade 6.0 software. X-Ray diffraction pattern shows $2 \theta$ values at $31.84^{\circ}, 34.52^{\circ}, 36.38^{\circ}, 47.64^{\circ}, 56.7^{\circ}, 63.06^{\circ}, 68.1^{\circ}$ and $69.18^{\circ}$. All evident peaks could be indexed as the Zinc oxidewurtzite structure (JCPDS Data Card No: 36-1451). Zinc oxide crystallizes in two main forms, hexagonal wurtzite and cubic zincblende. The wurtzite structure is most stable at ambient conditions and thus most common. It also confirms the synthesized nanopowder was free of impurities as it does not contain any characteristics XRD peaks other than zinc oxide peaks [44].

\subsection{Dynamic Light Scattering (DLS) Analysis}

Particle size was determined by dynamic light scattering technique using Nano plus (Micromeritics, USA).The instrument can measure the particle size of samples suspended in liquids in the range of $0.1 \mathrm{~nm}$ to $12.3 \mu \mathrm{m}$ with sample suspension concentrations from $0.00001 \%$ to $40 \%$, plus a sensitivity for molecular weight to as low as $250 \mathrm{Da}$. Dynamic light scattering is a widely used technique for the determination of particle size in colloidal solution. The average size of the particles, size distribution, and polydispersity index (PDI) of the synthesized zinc oxide nanoparticles were determined by this technique and the results are shown in Figure 4. The resulting particle size of zinc oxide nanoparticles exhibits the size distribution starting from 78 to $145 \mathrm{~nm}$. It shows the average particle size of $145.1 \mathrm{~nm}$ which is in well agreement with scanning electron microscopy analysis results which are shown below in the figure number 7 (a) and 7 (b). Polydispersity index found was 0.189 which indicates synthesized particles are monodispersed.

\subsection{Zeta Potential Analysis}

Zeta potential analysis was carried out to detect the surface charges acquired by zinc oxide nanoparticles, which can be used to gain further insights into the stability of the obtained colloidal zinc oxide nanoparticles. Zeta potential of zinc oxide nanoparticle 


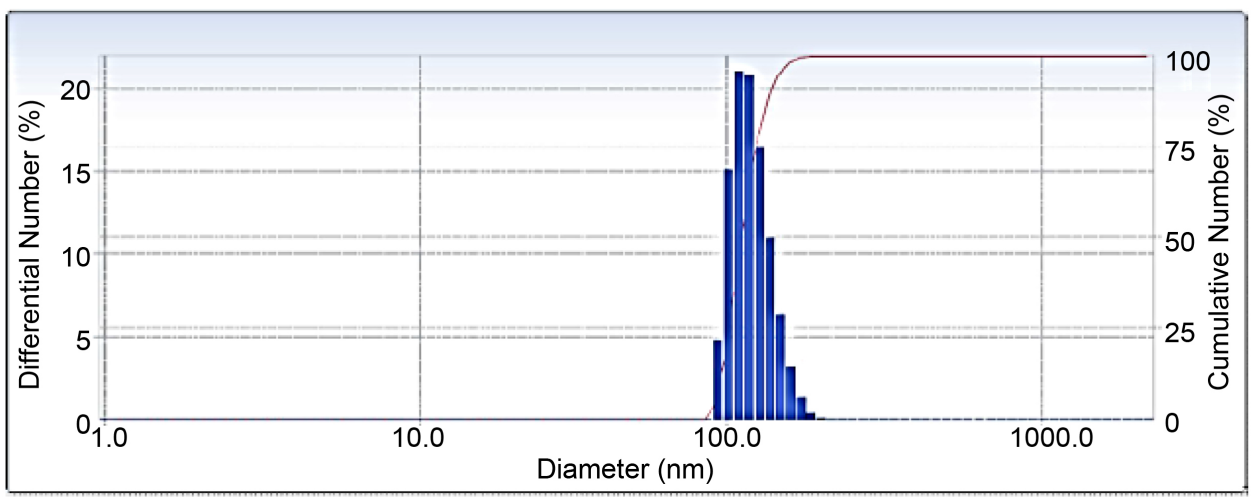

Figure 4. Particle size distribution of synthesized zinc oxide nanoparticles.

was measured using instrument provided by Nanoplus-Micromeritics, USA. This instrument has the ability to perform highly accurate zeta potential measurements of sample suspensions in the $-500 \mathrm{mV}$ to $+500 \mathrm{mV}$ range. Patented FST technology utilizes a transparent electrode to minimize path length and reduce multiple scattering effects. The magnitude of zeta potential gives an insinuation of potential stability of colloid. If the particles in a suspension have large negative or positive zeta potential values, particles will repel each other and there will be no aggregation of nanoparticles. On the other hand, if particles have small zeta potential values there is no force to prevent particle coming together and their aggregation. It is generally considered that the zeta potential values greater than $+30 \mathrm{mV}$ or smaller than $-30 \mathrm{mV}$, result in stable suspensions [45]. The zeta potential of the synthesized zinc oxide nanoparticles was determined in water as dispersant. The zeta potential was found to be $-49.19 \mathrm{mV}$ as shown in Figure 5. The high value confirms the repulsion among the particles and thereby increases in stability of the formulation [46].

\subsection{Fourier Transform Infrared Spectroscopy (FT-IR) Analysis}

FT-IR is an effective method to reveal the composition of products. Figure 6 is a typical FTIR spectrum of pure zinc oxide nanoparticles and Table 1 indicates absorption spectrum with possible assignments. Peak at $533 \mathrm{~cm}^{-1}$ is the characteristic absorption of $\mathrm{Zn}-\mathrm{O}$ bond and the broad absorption peak at $3398 \mathrm{~cm}^{-1}$ can be attributed to the characteristic absorption of hydroxyl. These data are similar to the results observed by others [47].

\subsection{Scanning Electron Microscopy (SEM) Analysis}

The morphology of the prepared nanoparticles was examined using scanning electron microscopy. Figure 7(a) and Figure 7(b) show the surface morphology of the zinc oxide nanoparticles under different magnifications. The SEM image showed that most of the nanoparticles are spherical in shape formed within diameter range of $80-130 \mathrm{~nm}$.

\subsection{Energy Dispersive X-Ray Diffractive (EDX) Analysis}

The Energy Dispersive X-ray Diffractive (EDX) study was carried out for the synthesized 
Mobility Distribution

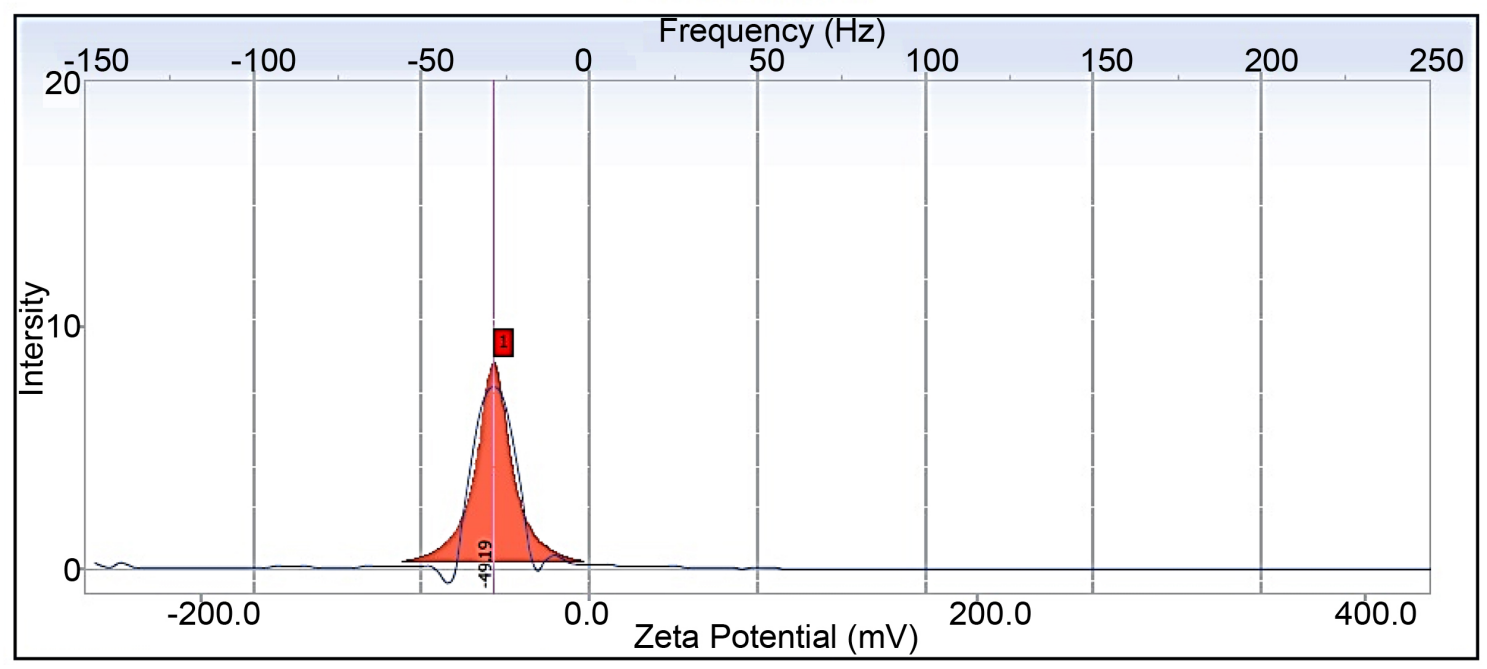

Figure 5. Zeta potential analysis of synthesized zinc oxide nanoparticles.

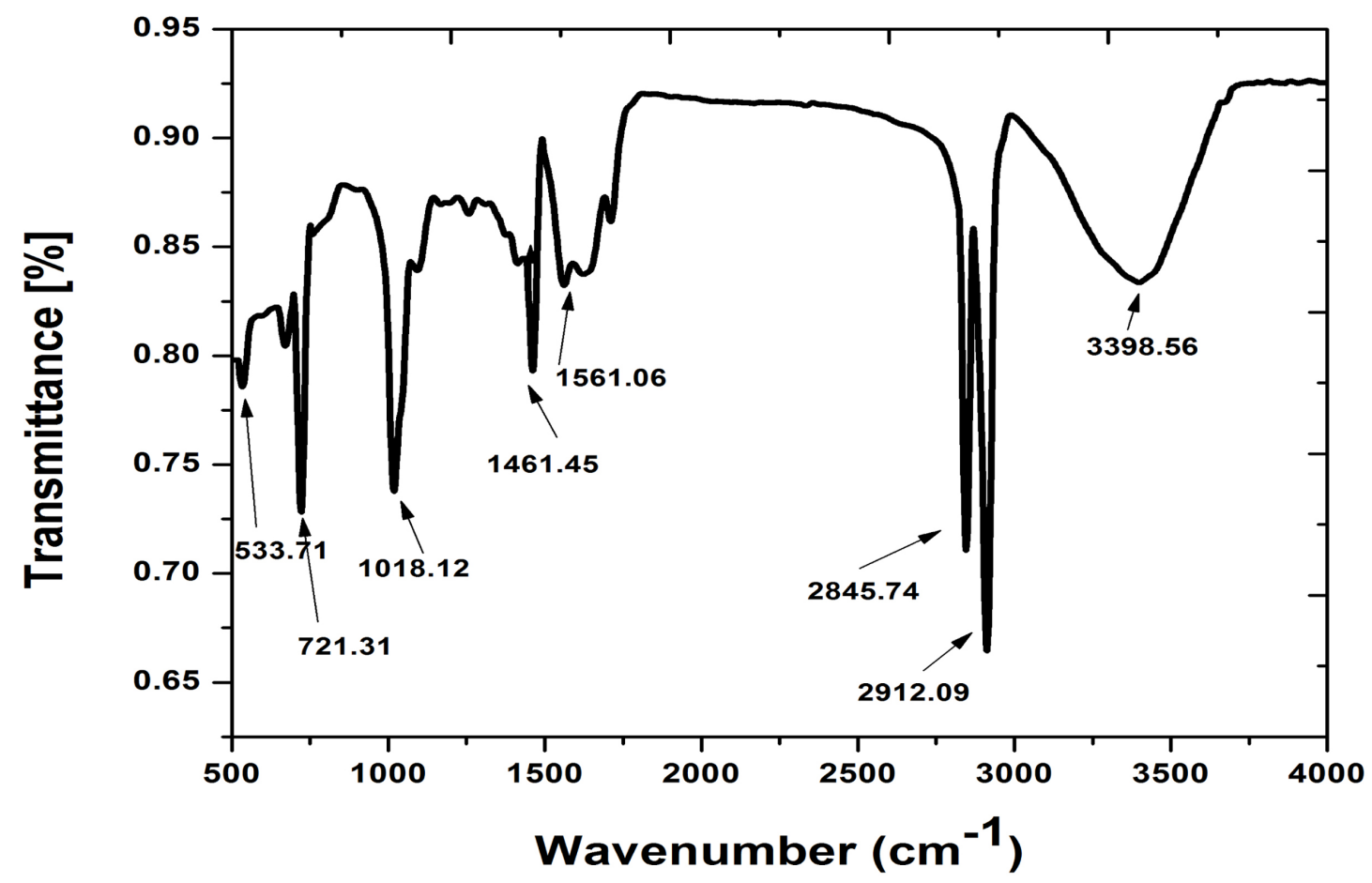

Figure 6. FTIR Spectra of synthesized zinc oxide nanoparticle.

zinc oxide nanoparticles to know about the elemental composition. EDX confirms the presence of zinc and oxygen signals of zinc oxide nanoparticle as shown in Figure 8 and this analysis showed the peaks that corresponded to the optical absorption of the produced nanoparticle. The elemental analysis of the nanoparticle yielded $77.56 \%$ of zinc and $22.44 \%$ of oxygen which proves that the produced nanoparticle is in its highest purified form. 

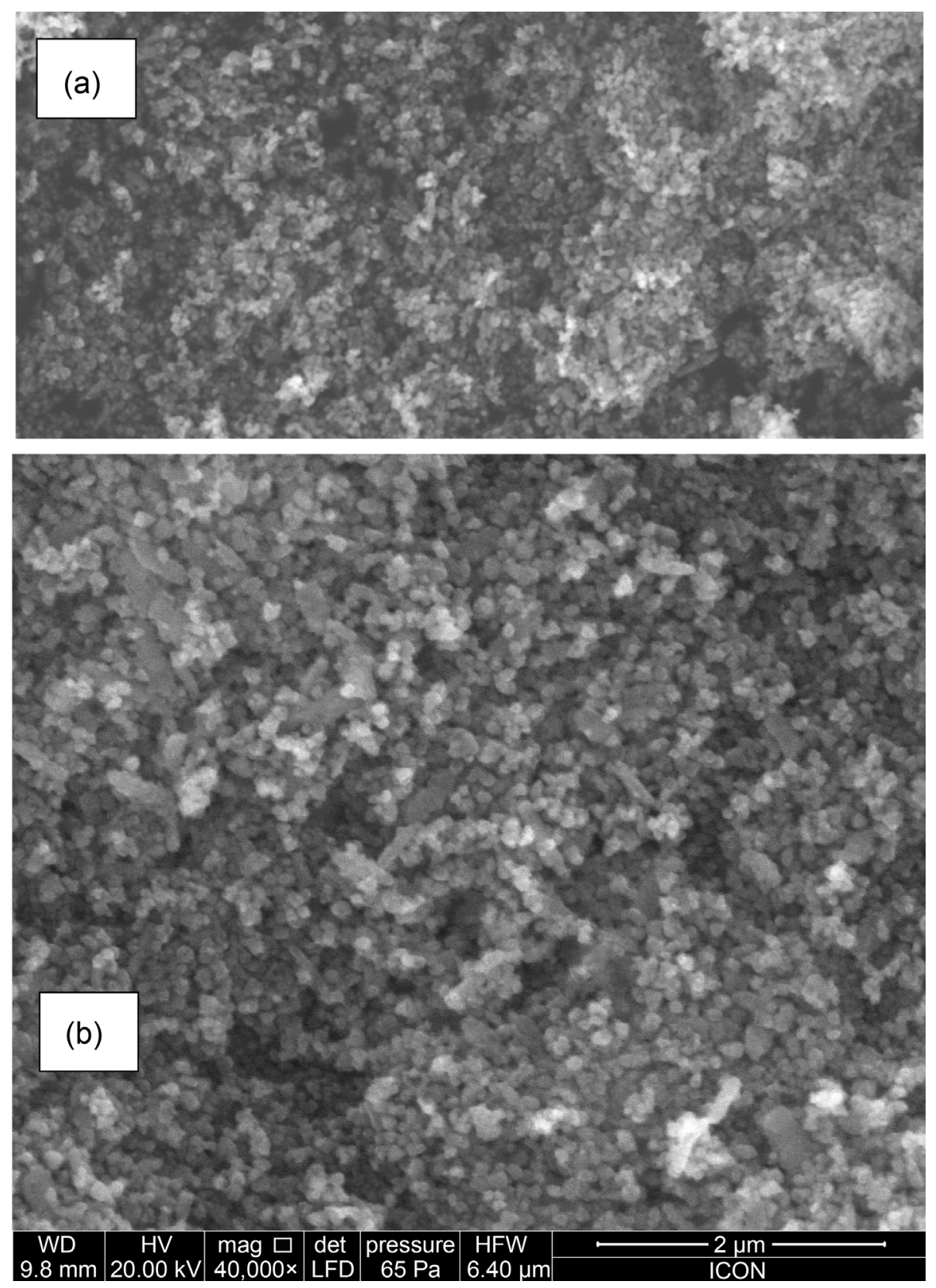

Figure 7. (a) and (b) SEM image of the synthesized zinc oxide nanoparticles.

Table 1. FTIR spectra with possible assignments.

\begin{tabular}{cc}
\hline Frequency $(\mathrm{cm})^{-1}$ & Possible Assignment \\
\hline $3398.56 \mathrm{~cm}^{-1}$ & OH stretching vibrations \\
$2912.09 \mathrm{~cm}^{-1}$ & The C-H stretch in alkanes \\
$2845.74 \mathrm{~cm}^{-1}$ & O-H stretch in carboxylic acid \\
$1561.06 \mathrm{~cm}^{-1}$ & $\mathrm{C}=\mathrm{C}$ stretch in aromatic ring and C=O stretch in polyphenols \\
$1461.45 \mathrm{~cm}^{-1}$ & $\mathrm{C}-\mathrm{N}$ stretch of amide-I in protein \\
$1018.12 \mathrm{~cm}^{-1}$ & $\mathrm{C}-\mathrm{O}$ stretching in amino acid \\
$533.71 \mathrm{~cm}^{-1}$ & hexagonal phase $\mathrm{ZnO}$ \\
\hline
\end{tabular}




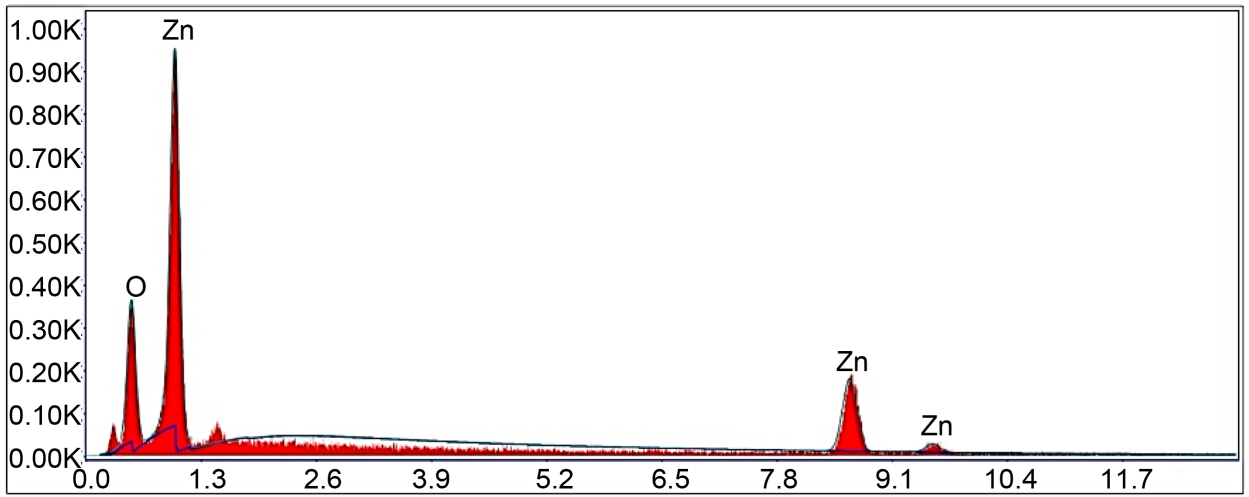

Figure 8. EDX spectrum of synthesized zinc oxide nanoparticles.

\section{Conclusion}

The rapid biological synthesis of zinc oxide nanoparticles using leaf extract of Ixora coccinea provides an environmental friendly, simple and efficient route for synthesis of nanoparticles. Zinc oxide nanoparticles have been successfully synthesized by using this method. The prepared zinc oxide nanoparticles were spherical in shape and were characterized using XRD, FTIR, EDX, DLS, UV-Vis absorption and SEM techniques. The SEM image showed that most of the nanoparticles are spherical in shape formed within diameter range of $80-130 \mathrm{~nm}$. FTIR shows that peak at $533.71 \mathrm{~cm}^{-1}$ is the characteristic absorption of zinc oxide bond which confirms formation of zinc oxide nanoparticles. X-ray diffraction confirms the formation of a hexagonal wurtzite phase which is the most stable form of zinc oxide at ambient conditions. Particle size of $145.1 \mathrm{~nm}$ and polydispersity index of 0.189 were found, which indicates there is uniform size distribution of nanoparticles. The zeta potential was found to be $-49.19 \mathrm{mV}$. The high value confirms the stability of zinc oxide nanoparticles. Zinc oxide nanoparticles prepared from above mentioned route are expected to have more extensive application in biotechnology, sensors, medical, catalysis, optical device, coatings, drug delivery and water remediation. Also, they may be applied for electronic and magneto-electric devices. This process is an economical method for the preparation of nanocrystalline zinc oxide with respect to energy, time and simplicity as well as it has high yield of $96.7 \%$ and can be used for large scale synthesis of zinc oxide nanoparticles.

\section{References}

[1] Daniel, M.C. and Astruc, D. (2004) Gold Nanoparticles: Assembly, Supramolecular Chemistry, Quantum-Size-Related Properties, and Applications toward Biology, Catalysis, and Nanotechnology. Chemical Reviews, 104, 293-346. http://dx.doi.org/10.1021/cr030698+

[2] Bogunia-Kubik, K. and Sugisaka, M. (2002) From Molecular Biology to Nanotechnology and Nanomedicine. BioSystems, 65, 123-138.

http://dx.doi.org/10.1016/S0303-2647(02)00010-2

[3] Zharov, V.P., Kim, J.W., Curiel, D.T and Everts, M. (2005) Self-Assembling Nanoclusters in Living Systems: Application for Integrated Photothermal Nanodiagnostics and Nanotherapy. Nanomedicine: Nanotechnology, Biology, and Medicine, 1, 326-345. 
http://dx.doi.org/10.1016/j.nano.2005.10.006

[4] Long, T.C., Saleh, C.N., Tilton, R.D., Lowry, G.V. and Veronesi, B. (2006) Titanium Dioxide (P25) Produces Reactive Oxygen Species in Immortalized Microglia (Bv2): Implications for Nanoparticle Neurotoxicity.| Environmental Science \& Technology, 40, 4346-4352. http://dx.doi.org/10.1021/es060589n

[5] Magrez, S., Kasas, V., Salicio, N., Pasquier, J., Seo, W., Celio, M., Catsicas, S., Schwaller, B. and Forro, L. (2006) Cellular Toxicity of Carbon-Based Nanomaterials. Nano Letters, 6, 1121-1125. http://dx.doi.org/10.1021/nl060162e

[6] Nel, A., Xia, T., Madler, L. and Li, N. (2006) Toxic Potential of Materials at the Nano Level. Science, 311, 622-627. http://dx.doi.org/10.1126/science.1114397

[7] Dagdeviren, C., Hwang, S.W., Su, Y., Kim, S., Cheng, H., Gur, O., Haney, R., Omenetto, F. G., Huang, Y. and Rogers, J.A. (2013) Transient, Biocompatible Electronics and Energy Harvesters Based on ZnO. Small, 9, 3398-3404. http://dx.doi.org/10.1002/smll.201300146

[8] Wang, L., Kang, Y., Liu, X., Zhang, S., Huang, W. and Wang, S. (2012) ZnO Nanorod Gas Sensor for Ethanol Detection. Sensors \& Actuators, B: Chemical, 162, 237-243. http://dx.doi.org/10.1016/j.snb.2011.12.073

[9] Cross, S.E., Innes, B., Roberts, M.S., Tsuzuki, T., Robertson, T.A. and McCormick, P. (2007) Human Skin Penetration of Sunscreen Nanoparticles: In-Vitro Assessment of a Novel Micronized Zinc Oxide Formulation. Skin Pharmacology and Physiology, 20, 148-154. http://dx.doi.org/10.1159/000098701

[10] Zhou, J., Xu, N. and Wang, Z.L. (2006) Dissolving Behavior and Stability of ZnO Wires in Biofluids: A Study on Biodegradability and Biocompatibility of ZnO Nanostructures. Advanced Materials, 18, 2432-2435. http://dx.doi.org/10.1002/adma.200600200

[11] Rasmussen, J.W., Martinez, E., Louka, P. and Wingett, D.G. (2010) Zinc Oxide Nanoparticles for Selective Destruction of Tumor Cells and Potential for Drug Delivery Applications. Expert Opinion on Drug Delivery, 7, 1063-1077.

http://dx.doi.org/10.1517/17425247.2010.502560

[12] Raveendran, P., Fu, J. and Wallen, S.L. (2003) Completely “Green” Synthesis and Stabilization of Metal Nanoparticles. Journal of the American Chemical Society, 125, 13940-13941. http://dx.doi.org/10.1021/ja029267j

[13] Narayanan, K.B. and Sakthivel, N. (2010) Biological Synthesis of Metal Nanoparticles by Microbes. Advances in Colloid and Interface Science, 156, 1-13. http://dx.doi.org/10.1016/j.cis.2010.02.001

[14] Narayanan, S., Sathy, B.N., Mony, U., Koyakutty, M., Nair, S.V. and Menon, D. (2012) Biocompatible Magnetite/Gold Nanohybrid Contrast Agents via Green Chemistry for MRI and CT Bioimaging. ACS Applied Materials \& Interfaces, 4, 251-260. http://dx.doi.org/10.1021/am201311c

[15] Govindaraju, K., Khaleel, B.S., Ganesh, K.V. and Singaravelu, G. (2008) Silver, Gold and Bimetallic Nanoparticles Production Using Single-Cell Protein (Spirulina platensis) Geitler. Journal of Materials Science, 43, 5115-5122. http://dx.doi.org/10.1007/s10853-008-2745-4

[16] Lengke, M.F., Fleet, M.E. and Southam, G. (2007) Biosynthesis of Silver Nanoparticles by Filamentous Cyanobacteria from a Silver(I) Nitrate Complex. Langmuir, 23, 2694-2699. http://dx.doi.org/10.1021/la0613124

[17] Kowshik, M., Deshmukh, N., Vogel, W., Urban, J., Kulkarni, S.K. and Paknikar, K.M. (2002) Microbial Synthesis of Semiconductor CdS Nanoparticles, Their Characterization, and Their Use in the Fabrication of an Ideal Diode. Biotechnology and Bioengineering, 78, 583-588. http://dx.doi.org/10.1002/bit.10233 
[18] Rautaray, D., Ahmad, A. and Sastry, M. (2003) Biosynthesis of $\mathrm{CaCO}_{3}$ Crystals of Complex Morphology Using a Fungus and an Actinomycete. Journal of the American Chemical Society, 125, 14656-14657. http://dx.doi.org/10.1021/ja0374877

[19] Lobiak, E.V., Shlyakhova, E.V., Bulusheva, L.G., Plyusnin, P.E., Shubin, Yu.V. and Okotrub, A.V. (2015) Ni-Mo and Co-Mo Alloy Nanoparticles for Catalytic Chemical Vapor Deposition Synthesis of Carbon Nanotubes. Journal of Alloys and Compounds, 621, 351-356. http://dx.doi.org/10.1016/j.jallcom.2014.09.220

[20] Cho, J.M., Song, J.K. and Park, S.M. (2009) Characterization of ZnO Nanoparticles Grown by Laser Ablation of a $\mathrm{Zn}$ Target in Neat Water. Bulletin of the Korean Chemical Society, 30, 1616-1618. http://dx.doi.org/10.5012/bkcs.2009.30.7.1616

[21] Wang, C., Shen, E., Wang, E., Gao, L., Kang, Z., Tian, C., Lan, Y. and Zhang, C. (2006) Controlable Synthesis of ZnO Nanoparticles via a Surfactant Assisted Alcohol Thermal Process at Low Temperature. Current Applied Physics, 6, 499-502.

[22] Lin, C. and Li, Y. (2009) Synthesis of ZnO Nanowires by Thermal Decomposition of Zinc Acetate Dihydrate. Materials Chemistry and Physics, 113, 334-337. http://dx.doi.org/10.1016/j.matchemphys.2008.07.070

[23] Hasnidawani, J.N., Azlina, H.N., Norita, H., Bonnia, N.N., Ratim, S. and Ali, E.S. (2016) Synthesis of ZnO Nanostructures Using Sol-Gel Method. Procedia Chemistry, 19, 211-216. http://dx.doi.org/10.1016/j.proche.2016.03.095

[24] Kharissova, O.V., Rasika, H.V. Kharisov, D.B.I., Pérez, B.O. and Jiménez Pérez, V.M. (2013) The Greener Synthesis of Nanoparticles. Trends in Biotechnology, 31, 240-248. http://dx.doi.org/10.1016/j.tibtech.2013.01.003

[25] Kumar, B., Smita, K., Cumbal, L. and Debut, A. (2014) Sacha inchi (Plukenetia volubilis L.) Shell Biomass for Synthesis of Silver Nanocatalyst. Journal of Saudi Chemical Society, in Press. http://dx.doi.org/10.1016/j.jscs.2014.03.005

[26] Haverkamp, R.G. and Marshall, A.T. (2009) The Mechanism of Metal Nanoparticle Formation in Plants: Limits on Accumulation. Journal of Nanoparticle Research, 11, 1453-1463. http://dx.doi.org/10.1007/s11051-008-9533-6

[27] Kumar, B., Smita, K., Cumbal, L. and Debut, A. (2014) Biogenic Synthesis of Iron Oxide Nanoparticles for 2-Arylbenzimidazole Fabrication. Journal of Saudi Chemical Society, 18, 364-369. http://dx.doi.org/10.1016/j.jscs.2014.01.003

[28] Saifuddin, N., Wong, C.W. and Yasumira, A.A.N. (2009) Rapid Biosynthesis of Silver Nanoparticles Using Culture Supernatant of Bacteria with Microwave Irradiation. E-Journal of Chemistry, 6, 61-70. http://dx.doi.org/10.1155/2009/734264

[29] Appierot, G., Lipovsky, A., Dror, R., Perkas, N., Nitzan, Y., Lubart, R. and Gedanken, A. (2009) Enhanced Antibacterial Actiwity of Nanocrystalline ZnO Due to Increased ROSMediated Cell Injury. Advanced Functional Materials, 19, 842-852. http://dx.doi.org/10.1002/adfm.200801081

[30] Sharma, D., Rajput, J., Kaith, B., Kaur, S.M. and Sharma, S. (2010) Synthesis of ZnO Nanoparticles and Study of Their Antibacterial and Antifungal Properties. Thin Solid Films, 519, 1224-1229. http://dx.doi.org/10.1016/j.tsf.2010.08.073

[31] Sangeetha, G., Rajeshwari, S. and Venckatesh, R. (2011) Green Synthesis of Zinc Oxide Nanoparticles by Aloe Barbadensis Miller Leaf Extract: Structure and Optical Properties. Materials Research Bulletin, 46, 2560-2566. http://dx.doi.org/10.1016/j.materresbull.2011.07.046

[32] Qu, J., Yuan, X., Wang, X. and Shao, P. (2011) Zinc Accumulation and Synthesis of ZnO Nanoparticles Using Physalis alkekengi L. Environmental Pollution, 159, 1783-1788. 
http://dx.doi.org/10.1016/j.envpol.2011.04.016

[33] Rajiv, P., Rajeshwari, S. and Venckatesh, R. (2013) Bio-Fabrication of Zinc Oxide Nanoparticles Using Leaf Extract of Parthenium hysterophorus L. and Its Size-Dependent Antifungal Activity against Plant Fungal Pathogens. Spectrochimica Acta Part A: Molecular and Biomolecular Spectroscopy, 112, 384-387. http://dx.doi.org/10.1016/j.saa.2013.04.072

[34] Anand Raj, L.F.A. and Jayalakshmy, E. (2015) Biosynthesis and Characterization of Zinc Oxide Nanoparticles Using Root Extract of Zingiber officinale. Oriental Journal of Chemistry, 31, 51-56. http://dx.doi.org/10.13005/ojc/310105

[35] Bhuyan, T., Mishra, K., Khanuja, M. and Prasad, R. (2015) Biosynthesis of Zinc Oxide Nanoparticles from Azadirachta indica for Antibacterial and Photocatalytic Applications. Materials Science in Semiconductor Processing, 32, 55-56.

http://dx.doi.org/10.1016/j.mssp.2014.12.053

[36] Rajiv, P., Rajeshwari, S. and Venckatesh, R. (2013) Rambutan Peels Promoted Biomimetic Synthesis of Bioinspired Zinc Oxide Nanochains for Biomedical Applications. Spectrochimica Acta Part A: Molecular and Biomolecular Spectroscopy, 112, 384-387. http://dx.doi.org/10.1016/j.saa.2013.04.072

[37] Wang, X.X., Wu, L., Zhou, P., Li, C., Zhao, L.B., An. W. and Chen, Y. (2014) Effect of ZnO Nanoparticles on Medicago Sativa at the Germination Stage. Applied Mechanics \& Materials, 665, 583-586. http://dx.doi.org/10.4028/www.scientific.net/AMM.665.583

[38] Anbuvannana, M., Rameshb, M., Viruthagiria, G., Shanmugama, N. and Kannadasana, N. (2015) Anisochilus carnosus Leaf Extract Mediated Synthesis of Zinc Oxide Nanoparticles for Antibacterial and Photocatalytic Activities. Materials Science in Semiconductor Processing, 39, 621-628. http://dx.doi.org/10.1016/j.mssp.2015.06.005

[39] Nagajyothi, P.C., An, T.N.M., Sreekanth, T.V.M., Lee, D.J. and Lee, K.D. (2013) Green Route Biosynthesis: Characterization and Catalytic Activity of $\mathrm{ZnO}$ Nanoparticles. Materials Letters, 108, 160-163. http://dx.doi.org/10.1016/j.matlet.2013.06.095

[40] Bala, N., Saha, S., Chakraborty, M., Maiti, M., Das, S., Basub, R. and Nandyc, P. (2015) Green Synthesis of Zinc Oxide Nanoparticles Using Hibiscus subdariffa Leaf Extract: Effect of Temperature on Synthesis, Anti-Bacterial Activity and Anti-Diabetic Activity. RSC Advances, 5, 4993-5003. http://dx.doi.org/10.1039/C4RA12784F

[41] Samat, N.A. and Nor, R.M. (2013) Sol-Gel Synthesis of Zinc Oxide Nanoparticles Using Citrus Aurantifolia Extracts. Ceramics International, 39, S545-S548. http://dx.doi.org/10.1016/j.ceramint.2012.10.132

[42] Baliga, M.S. and Kurian, P.J. (2012) Ixora coccinea Linn.: Traditional Uses, Phytochemistry and Pharmacology. Chinese Journal of Integrative Medicine, 18, 72-79. http://dx.doi.org/10.1007/s11655-011-0881-3

[43] Imitan, S., Albonetti, S., Forni, L., Peri, F. and Lazzari, D. (2009) Solvothermal Synthesis and Properties Control of Doped ZnO Nanoparticles. Journal of Colloid and Interface Science, 329, 73-80. http://dx.doi.org/10.1016/j.jcis.2008.09.060

[44] Bigdeli, F., Morsali, A. and Retalleau, P. (2010) Synthesis and Characterization of Different zinc (II) Oxide Nano-Structures from Direct Thermal Decomposition of ID Coordination Polymers. Polyhedron, 29, 801-806. http://dx.doi.org/10.1016/j.poly.2009.10.027

[45] Meléndrez, M.F., Cardenas, G. and Arbiol, J. (2010) Synthesis and Characterization of Gallium Colloidal Nanoparticles. Journal of Colloid and Interface Science, 346, 279-287. http://dx.doi.org/10.1016/j.jcis.2009.11.069

[46] Garcia, A., Cuesta, A., Montes-Moran, M., Martinez-Alonso, A. and Tascon, J. (1997) Zeta Potential as a Tool to Characterize Plasma Oxidation of Carbon Fibers. Journal of Colloid 
and Interface Science, 192, 363-367. http://dx.doi.org/10.1006/jcis.1997.5007

[47] Srinivasa Rao, N. and Basaveswara Rao, M.V. (2015) Structural and Optical Investigation of $\mathrm{ZnO}$ Nanopowders Synthesized from Zinc Chloride and Zinc Nitrate. American Journal of Materials Science, 5, 66-68.

Submit or recommend next manuscript to SCIRP and we will provide best service for you:

Accepting pre-submission inquiries through Email, Facebook, LinkedIn, Twitter, etc. A wide selection of journals (inclusive of 9 subjects, more than 200 journals)

Providing 24-hour high-quality service User-friendly online submission system

Fair and swift peer-review system

Efficient typesetting and proofreading procedure

Display of the result of downloads and visits, as well as the number of cited articles Maximum dissemination of your research work

Submit your manuscript at: http://papersubmission.scirp.org/

Or contact ojsta@scirp.org 